\title{
Knowledge, Attitude and Practice of Private Medical Practitioners in Calabar towards Post-Abortion Care
}

\author{
SJ Etuk ${ }^{1}$, IF Ebong ${ }^{2}$ and FE Okonofua ${ }^{3}$
}

\begin{abstract}
This study examined the knowledge, attitude and practice of private medical practitioners in Calabar on abortion, postabortion care and post-abortion family planning. Forty eight private practitioners who were proprietors of private clinics in the city were interviewed using a structured questionnaire. The results showed that $22.9 \%$ of the doctors routinely terminate unwanted pregnancies when requested to do so by women, while $83.3 \%$ of them treat women who experience complications of unsafe abortion. The major reasons given by some of the doctors for not terminating unwanted pregnancies were religious, moral and ethical considerations rather than respect for the Nigerian abortion law. Only $18.2 \%$ of the doctors use standard procedures such as manual vacuum aspiration (MVA) for the management of patients with abortion and abortion complications. A good number of them did not routinely practice integrated post-abortion family planning and STDs management. There is need for a comprehensive programme of retraining of private medical practitioners in Calabar on the principles and practices of safe abortion, post-abortion care and family planning. These aspects of reproductive health need to be integrated into the medical training curricula in Nigeria. It is believed that this approach would help reduce the present high rate of abortion-related morbidity and mortality in Nigeria. (Afr J Reprod Health 2003; 7 [3]: 55-64)
\end{abstract}

\section{RÉSUMÉ}

Connaissance, attitude et pratique des praticiens médicaux privés à Calabar envers les soins post-avortements. Cette etude a examiné la connaissance, l'attitude et la pratique des praticiens médicaux privés à Calabar à l'égard de l'avortement, des soins de post-avortement et de la planifiction familiale du post-avortement. Nous avons interviewé 48 praticiens privés, propriétaires des cliniques privées dans la ville, à l'aide d'un questionnaire structuré. Les résultats ont montré que $22,9 \%$ des médecins interrompent systématiquement des grossesses non-désirées quand les femmes le demandent alors que 83,3\% d'eux soignent les femmes qui ont des complications des avortements dangereux. Les raisons principales données par certains médecins pour lesquelles ils interrompent les grossesses non-desirées étaient plutôt plus pour des considerations religieuses et morales que pour le respect pour la loi nigériane sur l'avortement. Seuls 18,2\% emploient des procedures normales telle l'aspiration pneumatique manuelle (APM) pour le traitement des patients qui ont des problèmes de l'avortement et des complications de l'avortement. Bon nombre d'eux ne pratiquent pas systématiquement la planification familiale du post-avortement intégré et du traitement des MSTs. Il faut un programme compréhensif du stage de recyclage des praticiens privés à Calabar sur les principes et les pratiques de l'avortement sans risque, les soins post-avortement et la planification familiale. Ces aspects de la santé reproductive doivent être intégrés dans le programme de la formation médicale au Nigéria. Nous espérons que cette approche aidera à réduire le présent taux élevé de la morbidité et de la mortalité lié à l'avortement au Nigéria. (Rev Afr Santé Reprod 2003; 7[3]: 55-64)

KEY WoRDs: Private medical practitioners, abortion, family planning, sexually transmitted infections

${ }^{1}$ Department of Obstetrics \& Gynaecology, College of Medical Sciences, University of Calabar, PMB 1115, Calabar, Nigeria. ${ }^{2}$ C/ o Mr. F. S. Ebong, Department of Economics, University of Calabar, PMB 1115, Calabar, Nigeria. ${ }^{3}$ Women's Health and Action Research Centre, 4 Alofoje Street, Off Uwasota Street, P.O. Box 10231, Ugbowo, Benin City, Nigeria.

Correspondence: Dr S.J. Etuk, Department of Obstetrics \& Gynaecology, College of Medical Sciences, University of Calabar, PMB 1115, Calabar, Nigeria. 


\section{Introduction}

Abortion is one of the major causes of maternal morbidity and mortality in most parts of subSaharan African countries. ${ }^{1-3}$ It accounts for about $40 \%$ of maternal deaths in some communities in Nigeria. ${ }^{2}$ Abortion has also been implicated as a cause of secondary infertility, ${ }^{4}$ ectopic pregnancy, ${ }^{5,6}$ mid-trimester spontaneous abortions ${ }^{7}$ and pre-term labour. ${ }^{1}$ These complications may not be unrelated to the fact that some women usually resort to clandestine and dangerous methods of pregnancy termination, mostly because of restrictive abortion laws in Nigeria. Several reports indicate that induced abortion is widespread in the country despite these prevailing restrictive abortion laws. ${ }^{8,9}$ A recent survey estimated that about 610,000 induced abortions are carried out in Nigeria annually. ${ }^{10}$ This ratio exceeds those from many other developing countries.

Several providers of abortion exist in Nigeria. These include orthodox public and private medical practitioners, paramedical professionals (pharmacists, patent medicine dealers, nurses/midwives, laboratory technologists and traditional practitioners). A study by Okonofua et $\mathrm{al}^{11}$ revealed that private medical practitioners are the most frequently used abortion providers by Nigerian women. Over $80 \%$ of the women who reported having had induced abortions indicated that private medical practitioners carried out the procedures. ${ }^{11}$ These include practitioners who work privately on a full time basis as well as public practitioners who provide abortion services on a part-time basis while working full time in public service. Although done by trained doctors, abortions provided by most private medical practitioners in Nigeria are largely unsafe. This is confirmed by the experiences of many tertiary hospitals that treat women with induced abortion complications., ${ }^{72-14}$ Besides, it is not certain that women receive any counselling after having abortions by private doctors as well as contraceptives to prevent a repeat abortion.

Private medical practitioners are an important group of professionals that can be targeted in efforts to improve women's access to safe post-abortion care in Nigeria. Before this can be done, there is need to understand the nature of abortion and post-abortion services provided by this group of professionals.
This will provide a framework for designing programmes to improve the quality of post-abortion care provided by private doctors in our community.

In June 2001, an initiative was developed to identify a framework for improving the quality of services for post-abortion care provided by private medical practitioners in Calabar. A formative study was carried out in the city to determine the knowledge, attitude and practice of private medical practitioners on issues relating to abortion and postabortion care. The results of this survey are presented in this paper. We believe these findings could form a basis for formulating appropriate interventions for improving the quality of postabortion care provided by private medical practitioners in Calabar.

\section{Methodology}

The study was carried out among private medical practitioners in Calabar, the capital city of Cross River State, located in the south-eastern part of Nigeria. It has an estimated population of 218,000. The inhabitants are mainly Efiks, Quas, Ejagham, Efut, Ibibio, Annang and other migrant workers. They are mainly civil servants, subsistent farmers, traders and fishermen. Most of them are Christians and only a few are Moslems. Monogamous marriage is highly practised; only few families are polygamous. There are four government-owned hospitals in Calabar with many registered private clinics. However, there are a few unregistered clinics, most of which are run by public service practitioners who provide private medical services on a part-time basis.

The largest number of private medical practitioners in the state is concentrated in Calabar. They have private clinics/hospitals where they provide post-abortion care and other medical services. Many of these clinics/hospitals are registered with the state Ministry of Health. Thus, at the onset of the study, we approached the state Ministry of Health in Calabar and obtained a list of private clinics/hospitals in the state for inclusion in the study. The list contained the names and addresses of 93 private clinics in the state as well as addresses of their proprietors. Of the 93, the number of clinics/hospitals registered in Calabar was 61. The 
list also contained the names of clinics that were no longer in existence or were managed by non-medical professionals. Hence, the number of clinics/hospitals that could potentially be enlisted in the study was less than the number obtained.

Consequently, we approached private practitioners who were proprietors of the identified clinics/hospitals in the city to explain the purpose and methods of the study. We sought their support for and consent to participate in the study. We further made inquiries of the unregistered private clinics in Calabar. Those identified were also enlisted for the study. Only those private practitioners who agreed to participate and returned the signed consent forms were included in the study. They were assured of confidentiality of information obtained from the study; the names of clinics or individual practitioners were not included in the study protocol and the interviews were conducted in private.

\section{Survey Methods}

A structured questionnaire was developed by a multidisciplinary team of social science and medical researchers for conducting the study in the participating clinics/hospitals. The questionnaire was organised in four broad sections. Section one solicited information on socio-demographic characteristics such as age, sex, marital status and educational background of the proprietors of the clinics that responded. In section two, we obtained information about the characteristics of the clinics / hospitals especially the patient load and the type of clinical services provided in the clinics/hospitals. In section three, information was obtained on the hospitals' experiences and practices of abortion and post-abortion care, i.e., whether they see women with unwanted pregnancies and abortion complications, how they handle such cases, the methods they use as well as the direct costs of services for abortion and post-abortion care. The final section of the questionnaire inquired about the attitudes and practices of the clinics regarding post-abortion care, family planning services and treatment of sexually transmitted infections and HIV in patients presenting with unwanted pregnancies, abortion and postabortion complications.
The questionnaire was pre-tested and validated before being administered on proprietors of the participating clinics/hospitals. Four field staff were recruited and trained on a uniform methodology for administering the questionnaire. They were requested to approach the respondents in their clinics in a sensitive and confidential manner. The questionnaire was self-completed and respondents had the option of completing it privately for collection later. Data obtained from the survey were analysed and formed the basis of our discussion and conclusion.

\section{Results}

\section{Characteristics of Respondents and Clinics}

Forty eight of the eligible private practitioners in Calabar participated in the study. Some of the doctors identified on the list from the Ministry of Health had either left the city or could not be located. Among those located, six refused to participate in the study.

Table 1 shows the socio-demographic characteristics of doctors who were proprietors of the clinics and who completed the study questionnaire. Their age ranged from 25 to 60 years. In all, 87.5\% of the doctors were male while $12.5 \%$ were female. Seventy five per cent of the doctors were married. The rest were single $(16.7 \%)$ or divorced/widowed (8.4\%). Most of the doctors (93.8\%) were Christians, while only one was a Moslem. Protestants were the most common among the Christian doctors (37.5\%), followed by Pentecostals (29.2\%) and Catholic (27.1\%).

Most of the doctors (56.3\%) were specialists, while $47.3 \%$ were general practitioners who had no postgraduate training in relevant medical subspecialties. The main specialist fields were obstetrics and gynaecology $(33.3 \%)$, surgery $(12.5 \%)$, internal medicine $(4.2 \%)$ and others (paediatrics, anaesthesiology, pathology and general practice) $(8.4 \%)$.

On the average, the clinics had two attending doctors (range 1-11) and five nurses (range 1-15). Many of the clinics offered appropriate and relevant ancillary services that would allow them to provide quality post-abortion care. These included obstetric and gynaecological services offered by $72.9 \%$ of the clinics, family planning services (77.1\%) and 
Table 1 Socio-Demographic Characteristics of Respondents

\begin{tabular}{lcc}
\hline Characteristics & Number of doctors & Percentage \\
\hline Sex & & \\
Male & 42 & 87.5 \\
Female & 6 & 12.5 \\
Total & 48 & 100.0 \\
& & \\
Marital status & & \\
Married & 36 & 75.0 \\
Single & 8 & 16.7 \\
Divorced & 3 & 6.3 \\
Others (widower) & 1 & 2.1 \\
Total & 48 & 100.0 \\
& & \\
Religion & & 27.1 \\
Catholic & 13 & 37.5 \\
Protestant & 18 & 2.1 \\
Muslim & 1 & 29.2 \\
Pentecostal & 14 & 2.1 \\
Grail Message & 1 & 2.1 \\
No response & 1 & 100.0 \\
Total & 48 & \\
Specialist & & 56.3 \\
Yes & & 43.7 \\
No & 27 & 100.0 \\
Total & 21 & \\
\hline
\end{tabular}

Median age and range $=45$ (25-60) years

treatment of STIs $(87.5 \%)$. Besides, $70.8 \%$ of the clinics had laboratory services, while $83.3 \%$ had surgical facilities.

\section{Attitude towards Unwanted Pregnancy and Abortion Complications}

When asked whether they managed women with unwanted pregnancies requesting induced abortion in their clinics, $42(87.5 \%)$ of the private medical practitioners agreed that they did. Some $56.3 \%$ of them managed at least one to two cases per week. One of them managed at least eight cases per week.
When asked about their attitude to such pregnancies, $22.9 \%$ of them said they assisted them in terminating the pregnancies. The mean number of terminations reportedly carried out each week per doctor was three. Thus, private medical practitioners in Calabar carried out about 33 terminations each week, amounting to 1,716 abortions per annum.

As shown in Table 2, among practitioners who would not terminate unwanted pregnancies, the majority indicated that they often espouse morality to such women and counsel them to continue with the pregnancies. Some $25.1 \%$ of the doctors often refer such women to clinics that perform 
Table 2 Methods of Resolving Unwanted Pregnancies for Women by Private Medical Practitioners

\begin{tabular}{|c|c|c|}
\hline Reason & Number of doctors & $\%$ \\
\hline *Terminate unwanted pregnancies & 11 & 22.9 \\
\hline \multicolumn{3}{|l|}{ *How do you resolve abortion problems if you do not terminate? } \\
\hline - Counsel to continue with pregnancy & 13 & 27.1 \\
\hline - Refer to other doctor & 3 & 6.3 \\
\hline - Counsel to continue and preach moral codes & 8 & 16.7 \\
\hline - Counsel to continue and refer to other doctor & 5 & 10.4 \\
\hline - Refer to other doctors and preach moral codes & 1 & 2.1 \\
\hline - Refer, counsel to continue and preach moral code & 3 & 6.3 \\
\hline - No response & 4 & 8.3 \\
\hline - Not applicable & 11 & 22.9 \\
\hline Total & 48 & 100.0 \\
\hline \multicolumn{3}{|l|}{$\begin{array}{l}\text { Extremely important reasons for not terminating unwanted } \\
\text { pregnancies }\end{array}$} \\
\hline - Religion & 24 & 50.0 \\
\hline - Against ethics & 18 & 37.5 \\
\hline - Against obligation & 18 & 37.5 \\
\hline Total & 48 & 100.0 \\
\hline \multicolumn{3}{|l|}{$\begin{array}{l}\text { Least important reasons for not terminating unwanted } \\
\text { pregnancies }\end{array}$} \\
\hline - Police harassment & 25 & 52.1 \\
\hline - Obedience to Nigerian law & 18 & 37.5 \\
\hline - Past experience of complication & 25 & 52.1 \\
\hline Total & 48 & 100.0 \\
\hline
\end{tabular}

terminations. The most important reason for refusing to terminate unwanted pregnancies was religious, followed by moral considerations, and the perception that abortion is against the ethics of their profession. None of the doctors mentioned obedience to the Nigerian abortion law or fear of police harassment as important reasons for not terminating unwanted pregnancies. Similarly, as shown in Table 2, fear of police harassment, past experience with abortion complications and obedience to the Nigerian abortion law were identified by practitioners as the least important reasons for their decision not to terminate unwanted pregnancies.

When asked whether they treated patients who experienced abortion complications in their clinics,
$83.3 \%$ of the doctors indicated that they did. The number of women with abortion complications managed in the clinics ranged from one to ten per week. The most common type of complications seen in the clinics was incomplete abortion (58.3\%), followed by septic abortion (12.5\%), haemorrhage $(22.9 \%)$, uterine perforation $(2.1 \%)$ and intraabdominal injuries $(2.1 \%)$.

\section{Methods Used for the Management of Unwanted Pregnancies and Abortion Complications}

Respondents who reported that they terminated unwanted pregnancy and treated incomplete abortions for women were asked to identify the methods they used in the first and second trimesters 
of pregnancy. Results of the analysis are shown in Table 3. The most common method used in the first trimester was dilatation and curettage (D \& C) $(36.4 \%)$, followed by manual vacuum aspiration (MVA) (18.2\%). Another 18.2\% indicated that they often combined MVA with D \& C, as they are often not satisfied with the results of MVA alone. Those who were not using MVA cited a lack of knowledge as the most important reason for non-use of the procedure. With regard to second trimester abortion, the results in Table 3 show that $36.4 \%$ of the doctors reported that they did not perform second trimester abortion or treated abortion complications in the second trimester of pregnancy, citing lack of expertise as the most important reason for not doing so. Most of them often referred patients to hospitals that have the expertise to manage them.

Most of those who reported performing abortion in the second trimester indicated that they did it with artificial rupture of fetal membranes (ARM), followed by uterine stimulation with high dose oxytocin. Other methods were artificial rupture of membranes alone and dilatation and curettage.
None of the doctors reported using medical methods of abortion such as mifepristone, misoprostol or methotrexate either in the first or second trimester.

The results reveal that $41.7 \%$ of the doctors reported that they had received formal training in the use of MVA. They received the training as part of residency training in teaching hospitals and/or during refresher courses. None of them were trained during their undergraduate education.

Furthermore, $56.2 \%$ of the doctors indicated that they had ever used MVA. The most important reason given for non-use among those who had never used MVA was unavailability of the equipment $(50.0 \%)$, followed by lack of familiarity with the method $(25.0 \%)$.

\section{Post-Abortion Family Planning and STDs Treatment}

In all, $72.9 \%$ of the doctors reported that they offered post-abortion family planning services; most of them offered family planning counselling and services.

\section{Table 3 Methods of Pregnancy Termination}

\begin{tabular}{lcc}
\hline Pregnancy duration & Number of doctors & $\%$ \\
\hline Pregnancy < 12 weeks & & \\
- D \& C & 4 & 36.4 \\
- MVA & 2 & 18.2 \\
- D \& C + MVA & 2 & 18.2 \\
- D \& C + ARM + oxytocin & 2 & 18.2 \\
- No response & 1 & 9.1 \\
Total & 48 & 100.0 \\
& & \\
Pregnancy > 12 weeks & 4 & 36.4 \\
- Do not do 2nd trimester abortion & 2 & 18.2 \\
- ARM & 3 & 27.3 \\
- ARM + oxytocin stimulation & 2 & 18.2 \\
- D \& C & 48 & 100.0 \\
Total & & \\
\hline
\end{tabular}

\footnotetext{
$D \& C=$ dilatation and curettage

$M V A=$ manual vacuum aspiration

$A R M=$ artificial rupture of fetal membranes
} 
Table 4 Post-Abortion Family Planning and STIs Treatment

\begin{tabular}{lcc}
\hline Family planning & Number of doctors & $\%$ \\
\hline *Offer post-abortion family planning & 35 & 72.9 \\
*Method used & & \\
- Offer FP counselling & 2 & 4.2 \\
- Offer FP counselling + services & 31 & 64.6 \\
& & \\
*Family planning products & & \\
- Pills & 35 & 62.9 \\
- Condoms & 29 & 60.4 \\
- IUCDs & 36 & 16.0 \\
- Foaming tablets & 8 & 12.5 \\
- Diaphragm & 6 & 56.3 \\
- Injectables & 27 & 47.9 \\
*Have IEC on family planning & 23 & 60.4 \\
* Screen patients for STDs & 29 & \\
*Method used for STIs screening & & 8.3 \\
- Inspect cervix for signs of infection & 4 & 8.3 \\
- Take high vaginal swab (HVS) & 4 & 6.3 \\
- Inspect cervix + HVS & 3 & 12.5 \\
- HIV screening + HVS & 6 & 25.0 \\
- HVS + inspect cervix + HIV screening & 12 & \\
& & \\
\hline
\end{tabular}

As shown in Table 4, many of the clinics reported that they had a broad range of family planning products including oral contraceptive pills $(72.9 \%)$, condoms $(60.4 \%)$ and intrauterine contraceptive device $(56.3 \%)$. By contrast, only a few reported that they had vaginal foaming tablets $(16.7 \%)$ and diaphragms (12.5\%). However, $47.9 \%$ reported that they had information, education and counselling (IEC) materials for counselling women about post-abortion care and post-abortion family planning.

Some $60.4 \%$ of the providers reported that they offered screening and treatment of STIs as part of their management of abortion. Many of them that they used high vaginal swab (HVS) for microbiological examination, inspection of the cervix and HIV screening. Only very few of the providers used syndromic management of their patients.

\section{Discussion}

This study shows that although $87.5 \%$ of the private medical practitioners in Calabar received women with unwanted pregnancies in their clinics only $22.9 \%$ routinely assisted them in terminating the pregnancies. Most of them would not terminate unwanted pregnancies but would counsel the women to keep the pregnancies or refer them to other doctors who did terminations. On the other hand, $83.3 \%$ of the doctors reported that they treated women who experienced complications of unsafe abortions especially those with incomplete and septic abortions. These results clearly show that unwanted pregnancies and abortion are major problems in Calabar. Despite the presence of restrictive abortion laws in Nigeria, respect for the law was not an important reason for doctors not terminating unwanted pregnancies. Religious, ethical and moral 
obligations were the most cited reasons for not terminating pregnancies.

MVA is currently the recommended method of choice for pregnancy termination or management of incomplete abortions in the first trimester, as it is easier to perform than the traditional D \& $\mathrm{C}$ and less likely to result in life-threatening complications. ${ }^{15,16}$ Only $18.2 \%$ of the private medical practitioners in Calabar used MVA alone for the routine management of abortion in the first trimester. Majority reported that they often used D \& C or combined MVA with D \& $\mathrm{C}$ in the management of abortion and abortion complications.

A large proportion of the doctors reported that they did not terminate pregnancies in the second trimester, while those who did used non-standard and inappropriate methods. The standard and safe methods for terminating pregnancies in the second trimester are dilatation and evacuation (D \& E) with cervical ripening using laminaria tents and prostaglandins ${ }^{17}$ and medical termination with misoprostol or mifepristone. ${ }^{18}$ By contrast, the vast majority of doctors in the sample reported that they used artificial rupture of membranes, followed by uterine stimulation with high dose oxytocin for the management of abortion and abortion complications in the second trimester. This method, which is now out-dated in many parts of the world, is likely to result in prolonged induction-evacuation intervals with high risk of reproductive tract infection and increased rates of maternal morbidity and mortality.

Findings from this study unfold a compelling need to provide continuing education to private medical practitioners in Calabar on the modern principles and practice of safe abortion care for women. Such education must include a description and practical demonstration of appropriate methods for managing abortion and abortion complications in the first and second trimesters of pregnancy. A complete absence of the use of medical abortificients such as misoprostol or mifepristone in the management of abortion complications as well as other methods like laminaria tents prostaglandins may likely be due to a lack of knowledge of these methods by the respondents or their non-availability in Nigeria. Thus, as part of the training, information on the mechanism of action of these alternative methods should be emphasised. Health care providers should also have access to agents for pregnancy termination.

The results of this study further suggest that the lack of knowledge of MVA was the most important reason for its non-use by doctors for the management of abortion and abortion complications in the first trimester. None of the doctors reported receiving training on MVA use during their undergraduate education. The few who had received training $(12.5 \%)$ were trained as part of their residency programme and/or under special refresher courses organised by teaching hospitals and specialist/military hospitals, with funding from the International Projects Assistance Services (IPAS). Thus, there is need for sustained and comprehensive programme of training on MVA and post-abortion care that would be integrated into all levels of medical education curriculum, undergraduate, postgraduate and continuing professional development. Such programmes would effectively increase the scope of knowledge of doctors on post-abortion care at all levels and reduce the incidence of complications associated with induced abortions in the country.

The results of this study suggest that $72.9 \%$ of the doctors provide post-abortion family planning services, while $60.4 \%$ offered integrated STIs treatment. This would be interesting if the doctors were not just providing "socially acceptable" answers. There is need to conduct exit interviews with women who have attended the clinics for management of abortion and abortion complications in order to establish the reliability of this information. Besides, physical inspection of the clinics to identify the facilities available, organisation of services for abortion, post-abortion and family planning would be helpful. However, less than $48.0 \%$ of the clinics reported that they had IEC materials for counselling women on post-abortion family planning and few reported the use of syndromic approach for STDs management despite the fact that they did not have standard laboratories. These observations suggest that the available facilities in these clinics may be less than optimal for providing post-abortion family planning and integrated STDs management.

In conclusion, private medical practitioners in Calabar perform termination of pregnancies or refer 
women with unwanted pregnancies to doctors who perform terminations and also treat those with abortion complications. However, the methods and procedures adopted for managing patients in the first and second trimesters of pregnancy do not conform to currently acceptable international standards and practices, and could contribute to the high rates of abortion-related morbidity and mortality in the country. There was sparse use of MVA and medical induction methods and inadequate conceptualisation of methods to integrate post-abortion care and STIs treatment into the management of women with abortion and abortion complications. We, therefore, strongly recommend the commencement of a comprehensive programme of retraining private practitioners as a principal short-term measure to address these issues in Nigeria. On a long-term basis, the theory and practice of safe abortion care should be incorporated into undergraduate and postgraduate medical curricula in the country. This would ensure that future doctors acquire knowledge on the acceptable methods of managing women with unwanted pregnancies and complications of unsafe abortion. This approach may provide a framework for achieving significant and sustainable reduction in abortion-related maternal morbidity and mortality in Nigeria.

\section{Acknowledgements}

We wish to thank the Women's Health and Action Research Centre (WHARC), Benin City, Nigeria, for sponsoring this project. We specially thank Mr. Frank Oronsaye for his cooperation and guidance during this project. We thank private medical practitioners in Calabar for their interest in participating in the study and also our field workers for their assistance during data collection. We are also grateful to Miss Glory Akpan for providing secretarial services.

\section{REFERENCES}

1. Okonofua FE. Preventing unsafe abortion in Nigeria. Afr J Reprod Health 1997; 1(1): 25-36.

2. Okonofua FE and Ilumoka A. Prevention of morbidity and mortality from unsafe abortion in
Nigeria. In: Critical Issues in Reproductive Health. New York: The population council, 1992.

3. Akingba JB. Abortion mortality and other health problems in Nigeria. Nig Med J 1977; 7(4): 465471.

4. Okonofua FE. Induced abortion: a risk factor for secondary infertility in Nigerian women. J Obstet Gynaecol 1994; 14: 272-276.

5. Olatunbosun $\mathrm{OA}$ and Okonofua FE. Ectopic pregnancy - the African experience. Postgrad Doct Africa 1986; 8(3): 74-78.

6. Orhue AAE, Unuigbe JA and Ogbeide WA. Contribution of previous induced abortion to tubal ectopic pregnancy. West Afr Med J 1989; 8: 257263.

7. Ladipo OA. Preventing and managing complications of induced abortion in third world countries. Int J Gynaecol Obstet 1989; 3: 21-28.

8. Okonofua FE, Onwudiegwu U and Odunsi OA. Illegal induced abortion: a study of 74 cases in IleIfe, Nigeria. Trop Doc 1992; 22: 175-176.

9. Adetoro OO. A 15-year study of illegally induced abortion at Ilorin, Nigeria. Int J Gynaecol Obstet 1989; 29: 65-68.

10. Henshaw SK, Singh S, Oye-Adeniran B, Adewole IF, et al. The incidence of induced abortion in Nigeria. Inter Fam Plann Persp 1998; 24(4): 156-164.

11. Okonofua FE, Odimegwu C, Ajabor H, et al. Assessing the prevalence and determinants of unwanted pregnancies and induced abortion in Nigeria. Stud Fam Plann 1999; 30: 67-77.

12. Okojie SE. Induced illegal abortion in Benin City, Nigeria. Int J Gynaecol Obstet 1976; 14(6): 517-521.

13. Archibong EI. Illegal induced abortion: a continuing problem in Nigeria. Int J Gynaecol Obstet 1991; 34: 261-267.

14. Megafu OA and Ozumba BC. Morbidity and mortality from induced abortion at the University of Nigeria Teaching Hospital, Enugu: a five-year review. Int J Gynaecol Obstet 1991; 34: 162-167.

15. Greenslade F, et al. Manual vacuum aspiration: a summary of clinical and programmatic experience worldwide, IPAS 1993.

16. King T, et al. Comparing the cost of post-abortion care in Africa and Latin America. The DataPac Project. Global meeting of post-abortion care, 1998. 
17. Porry KG, Rinehart BK, Terrone DA, Martin RW, May WL and Roberts WE. Second trimester uterine evacuation: a comparison of intra-aminotic (15515-methyl-prostroglandin $\mathrm{F}_{2}$ alpha) and intravaginal misoprostol. Am J Obstet Gynecol 1999; (5 pt 1): 1057-1061.
18. Jain JK, Meekstooth KR and Mishell DR Jr. Early pregnancy termination with intravaginal administered sodium chloride solution moistened misoprostol tablets: a historical comparison with mifeprostone and oral misoprostol. Am J Obstet Gynecol 1999; 181(6): 1386-91. 